\title{
Monetary policy and commodity price shocks
}

Silke Tober and Tobias Zimmermann

\section{October 2008}




\title{
Monetary policy and commodity price shocks
}

\author{
Silke Tober ${ }^{\#}$ and Tobias Zimmermann ${ }^{*}$
}

October 2008

\begin{abstract}
This paper analyses the effects of commodity price shocks in a new Keynesian model. The focus is on the central bank's choice of inflation target and the degree of real wage rigidity. It turns out that using core inflation rather than headline inflation is the superior strategy. Targeting expected headline inflation, as practiced by most central banks, is a viable practical alternative to the core inflation target. Simulations illustrate these points. The introduction of real wage rigidity into the model does not change these conclusions. Real wage rigidity does, however, imply second-round effects, making the monetary policy response, the inflation peak and the output drop more pronounced. Although in practice many of the assumptions of the model, such as full information, do not hold, lessons can be drawn for monetary policy. Faced with a commodity price shock, central banks would do well to focus on some measure of core inflation rather than headline inflation so as to reduce the volatility of both inflation and output. A communication strategy that places greater emphasis on underlying and expected inflation could serve to anchor inflation expectations.
\end{abstract}

\footnotetext{
Institute for Macroeconomic Analysis (IMK) in the Hans Boeckler Foundation, silke-tober@boeckler.de.

* Rhine-Westphalia Institute for Economic Research (RWI), tobias.zimmermann@rwi-essen.de.
} 


\section{Introduction}

How should central banks react to supply shocks? Given the drastic increases in the price of oil and other raw materials in the recent past, this is one of the key issues currently faced by central banks. In this paper, we explore what new Keynesian theory has to say about commodity price shocks and monetary policy. We focus on two key issues: real wage rigidity and the inflation indicator used by the central bank. In the first section we outline the effects of a negative supply shock in the medium and long run. We then discuss what happens in the short run given different assumptions about wage rigidity and the monetary policy strategy. Using a DSGE model we offer several simulation results. Section 3 draws lessons from section 2 about whether the central bank should target headline inflation, core inflation or expected inflation. The conclusion in section 4 applies the findings of the previous section to the current situation in the euro area.

\section{Effects of commodity shocks in and beyond the medium term}

Starting point is a standard new-Keynesian model of an oil-importing country that uses oil both as a consumer good and as an input in production (Blanchard/Gali 2008). ${ }^{1}$ A sharp permanent increase in the price of oil means that less of this factor will be employed in production. Furthermore, either real wages, employment or the mark-up have to decline. Unless there is a contemporaneous downward shift in the labor supply curve, the potential output of the economy will decline.

With oil more expensive and real wages lower, the return on capital increases. In the longer run, capital is therefore substituted for oil as investment in energy-efficient equipment and new energy technologies increases (Atkeson/Kehoe 1999). As a result, labor productivity increases, resulting in either higher real wages or higher employment or a bit of both - in either case, potential output once again reaches a higher level. Whether this potential output level is higher or lower than the one that would have been realized in the absence of an oil price shock depends, among other things, on the technological progress embedded in new production methods.

In the short run, there are frictions in the economy. How monetary policy reacts to the supply shock therefore affects how smoothly, and ultimately how fast, the economy reaches its new equilibrium. ${ }^{2}$

\footnotetext{
${ }^{1}$ See Clarida et al. (1999) and Woodford (2003) for a detailed exposition of the standard new Keynesian model.

2 The discussion here abstracts from potential long-term effects of monetary policy.
} 


\section{Monetary policy, rigidities and commodity shocks}

The "current best practice in monetary policy" is inflation targeting (Svensson 2008: 2). The term inflation targeting should be understood as inflation-forecast targeting (Svensson) or in the words of Bernanke (2004) as "forecast-based policy". Because of the lags with which the economy reacts to monetary-policy actions, central banks have to make use of forecasts. ${ }^{3}$ New Keynesian models (NKMs), however, often implement a Taylor rule. We therefore analyze the effects of both types of monetary policy strategies given different assumptions about real wage rigidity. ${ }^{4}$

\section{A simple NK model}

We begin with a model with no real wage rigidity. Nominal frictions that characterize NKMs are assumed to be relevant only in the non-commodity sector of the economy, i.e. in the core sector (Aoki 2001 and Lenza 2007). This assumption is reasonable because food and energy resources are at the most transformed into standardized goods, which are traded in nearcompetitive markets with frequent price adjustments.

Commodity prices change in response to supply or demand shifts. Although the recent price hike is to a large extent caused by a booming economy, especially in the emerging markets, and therefore demand-driven, from the point of view of the oil-importing industrialized countries it represents a supply shift.

NKMs were developed for business cycle analysis, i.e. shocks are usually modeled as stationary. However, the relative increase in energy and commodity inflation may be a more permanent phenomenon in view of the soaring demand from emerging markets such as China. Since it is not possible to forecast the relative prices for commodities with any accuracy, we also analyze the optimal monetary reaction to a permanent shock to commodity price inflation.

In the following, subscript $f$ marks the commodity sector, where fully flexible prices prevail. Subscript $s$ labels the remaining part of the model economy which is interpreted as the core sector. Relative prices, $X_{j, t}$, and sectorial inflation rates, $\pi_{j, t}$, are defined as

(1) $X_{j, t}=\frac{P_{j, t}}{P_{t}}$,

and

(2) $\pi_{j, t}=\log \left(\frac{P_{j, t}}{P_{j, t-1}}\right)$,

\footnotetext{
${ }^{3}$ Svensson (2008: 3) asserts that inflation targeting is in practice always flexible inflation targeting in the sense that it aims to stabilize both the real economy and inflation.

${ }^{4}$ As Duval/Vogel (2008: 6) point out, nominal price rigidities do not greatly influence the effects of oil price shocks and do not give rise to different economic responses to alternative monetary policy strategies, with one exception: If a central bank follows a Taylor rule and focuses on headline inflation, strong nominal price rigidity causes monetary tightening and output contraction to be more pronounced.
} 
respectively. $P_{j, t}$ and $P_{t}$ represent the price level in sector $j$ and the price level of the whole economy respectively. The model is loglinearized around a deterministic steady state with zero inflation. Since the model is well documented in the literature, we only present linearized equations. Loglinearizing the aggregate price index, $P_{t}=P_{s, t}^{\gamma} P_{f, t}^{1-\gamma}$, yields headline inflation, $\pi_{\mathrm{t}}$ :

(3) $\pi_{t}=\gamma \pi_{s, t}+(1-\gamma) \pi_{f, t}$

and

(4) $\pi_{t}=\pi_{s, t}+\frac{(1-\gamma)}{\gamma} \Delta x_{f, t}$

where $\gamma$ is the fraction of non-commodity goods in the aggregate consumption basket. $^{5}$ Sectorial output gaps, $\tilde{y}_{j, t}$ are defined as

(5) $\tilde{y}_{j, t}=y_{j, t}-y_{j, t}^{n}$

where $y_{j, t}^{n}$ is the natural level of output in the respective sector. Note that even if prices are fully flexible in the commodity sector, $y_{f, t}^{n}$ is not always zero, because a sub-optimal output level in the core sector would automatically imply sub-optimal goods consumption in the commodity sector. The aggregate output gap is defined as

(6) $\tilde{y}_{t}=\gamma\left(y_{t}-y_{s, t}^{n}\right)+(1-\gamma)\left(y_{t}-y_{f, t}^{n}\right)$.

Natural output levels in the respective sectors evolve exogenously, depending on the relative price level in the commodity sector.

Apart from definitions, the equilibrium dynamics of the model economy can be summarized by two equations that determine the output gap and core inflation. A new Keynesian IS equation, which describes the consumption-saving trade-off, can be derived from a standard Euler equation for consumption:

(7) $\tilde{y}_{t}=E_{t} \tilde{y}_{t+1}-\frac{1}{S}\left(i_{t}-E_{t} \pi_{s, t+1}-r_{t}^{n}\right)$

where $i_{t}$ represents the nominal interest rate. $S$ is a deep structural parameter of the model derived from preferences and the relative importance of the two sectors. Aggregate demand positively depends on the expected output gap, $\mathrm{E}_{t} \tilde{y}_{t+1}$, and the difference between the expected real interest rate and the natural real interest rate, $r_{t}^{n}$. The natural interest rate is the interest rate that would prevail in a fully flexible economy. The IS curve states that the expected slope of the temporal path of aggregate demand depends, among other things, on the expected real interest rate and therefore monetary policy.

A new Keynesian Phillips curve describes the relationship between inflation, expected inflation and the output gap in the sticky price sector:

(8) $\pi_{s, t}=\beta E_{t} \pi_{s, t+1}+\kappa \tilde{y}_{t}$

\footnotetext{
${ }^{5}$ The parameter $\gamma$ is calibrated to 0.9 .
} 
where $\kappa$ is a structural parameter that determines the link between output gap and inflation in the sticky price sector. Prices are sticky because only a fraction of firms can reset their prices in each period (Calvo 1983). The greater the price stickiness in the core sector of the economy, the flatter is the Phillips curve. Core inflation depends on expected core inflation since firms take into account their forecasts of future real marginal costs when they are able to modify their prices.

In the standard NKM, the structure of the economy, i.e. nominal frictions, serve as a constraint of the central bank. The central bank has to identify underlying shocks and use the equations that characterize the dynamics in the economy to restore the optimal levels of inflation and output. In the two-sector case, the evolution of the relative price of commodities must also be taken into account. The relative price of commodities depends positively on output and negatively on the natural output in the commodity sector.

(9) $x_{f, t}=c\left(y_{t}-y_{f, t}^{n}\right)$

where $c$ is a structural parameter of the model, corresponding to the preferences of private households. Combining this equation with equation (8), the new Keynesian Phillips curve can be augmented by relative price changes:

(10) $\pi_{s, t}=\beta E_{t} \pi_{s, t+1}+\kappa\left(\gamma\left(y_{t}-y_{s, t}^{n}\right)+\frac{1-\gamma}{c} x_{f, t}\right)$

Equation (10) states that the relative price of commodities enters into the Phillips curve and affects inflation in the sticky price sector. The mechanism in the model is the substitution between the flexible price good and the sticky price good. When the relative commodity price increases, households increase their relative demand for the sticky price goods. Facing an increase in demand (relative to supply), sellers in the core sector raise their prices. Our calibration assumes that only $25 \%$ of firms are able to change their price in each period, i.e. individual prices stay constant for approximately one year. The Taylor rule takes on the simplest possible form and assigns deviations from both policy objectives the same weight, so generally monetary policy is implemented by an equation of the following form: ${ }^{6}$ (11) $i_{t}=\pi_{j, t+k}+0.5\left(\pi_{j, t+k}-\bar{\pi}\right)+0.5 \tilde{y}_{t}$.

Based on this model we examine the effect of different shocks to the commodity price level, ranging from a non-permanent increase in the commodity price level to a permanent increase in commodity price inflation. As indicated by the specified Taylor rule, the central bank has a choice between targeting headline inflation and targeting core inflation. As a practical alternative we also consider the possibility that the central bank targets expected headline inflation. To illustrate the different effects of these three monetary policy objectives every simulation is performed three times: first, using headline inflation, $\pi_{t}$, second, using core inflation, $\pi_{s, t}$, and third, using expected headline inflation, $\pi_{t+4}$.

\footnotetext{
${ }^{6}$ Since the model is linearized around zero inflation, the Taylor rule collapses to $i_{t}=1.5 \pi_{j, t+k}+0.5 \tilde{y}_{t}$.
} 
Figure 1 shows how the interest rate, headline and core inflation, and the output gap react to a temporary but persistent oil price shock given the three Taylor rules introduced above. ${ }^{7}$ The simulations show that stabilizing core inflation is the superior monetary strategy: both output in the core sector and core inflation stay close to their optimal values. In a twosector model, the central bank should therefore focus on core inflation, not because it is useful to predict future inflation, but because by doing so the central bank can reduce market distortions in the sticky price sector and achieve an optimal allocation of resources (Mishkin 2007: 7; Woodford 2003). ${ }^{8}$ Furthermore, if core inflation is stabilized perfectly, changes in relative prices solely depend on changes in the potential output in both sectors. Demand factors do not affect relative prices and relative prices stay at their efficient levels. If the central bank instead focuses on headline inflation, the decline in output and nominal wages will be greater as will the variability of core inflation.

The output losses which occur when the central banks targets headline inflation can be avoided by focusing instead on one-year-ahead expected inflation. However, the positive counter reaction of the output gap does not diminish. As in the case of current headline inflation, core inflation is higher when central banks target expected headline inflation given a persistent but non-permanent shock: The reason is that inflation in the commodity sector becomes negative after the initial impulse and rational agents in the core sector, who know the evolution of relative prices, raise their prices more aggressively (Duval/Vogel 2008). Since both core inflation and output gap are more volatile, targeting core inflation also prevails over expected headline inflation.

In the simulation with the core-inflation Taylor rule the central bank raises interest rates because core inflation increases. The reason is the increase in the relative price of the commodity that lowers demand in this sector and raises it in the core sector. Given an oil price shock in practice, such a short-term increase in the demand for core goods seems rather unlikely because of the low price elasticity of energy demand and the low elasticity of substitution between goods in the commodity and the core sector. As a result, demand for core goods may actually fall.

The main results also apply to the case of a permanent shock to the relative price level in the commodity sector, because the focus on headline inflation causes core inflation and the output gap to fall before returning to its optimal level (Figure 2). If the central bank focuses instead on core or expected headline inflation none of these negative reactions occur. Nonetheless, expected headline inflation as a target will generate a small increase in interest rates, whereas focusing on core inflation leads to a small decrease in interest rates because core inflation is expected to fall in response to the negative output gap (because both reactions are so small they cannot be seen in Figure 2).

\footnotetext{
${ }^{7} x_{f, t}$ follows an $A R(1)$ process, $x_{f, t}=\rho x_{f, t-1}+u_{t} ; \rho$ is set to 0.8 .

${ }^{8}$ In the simulations, the central bank cannot stabilize both targets perfectly, because monetary policy is implemented by a simple feedback rule depending on realized variables.
} 
Figure 1: Responses of nominal variables and the output gap to a persistent increase in commodity prices
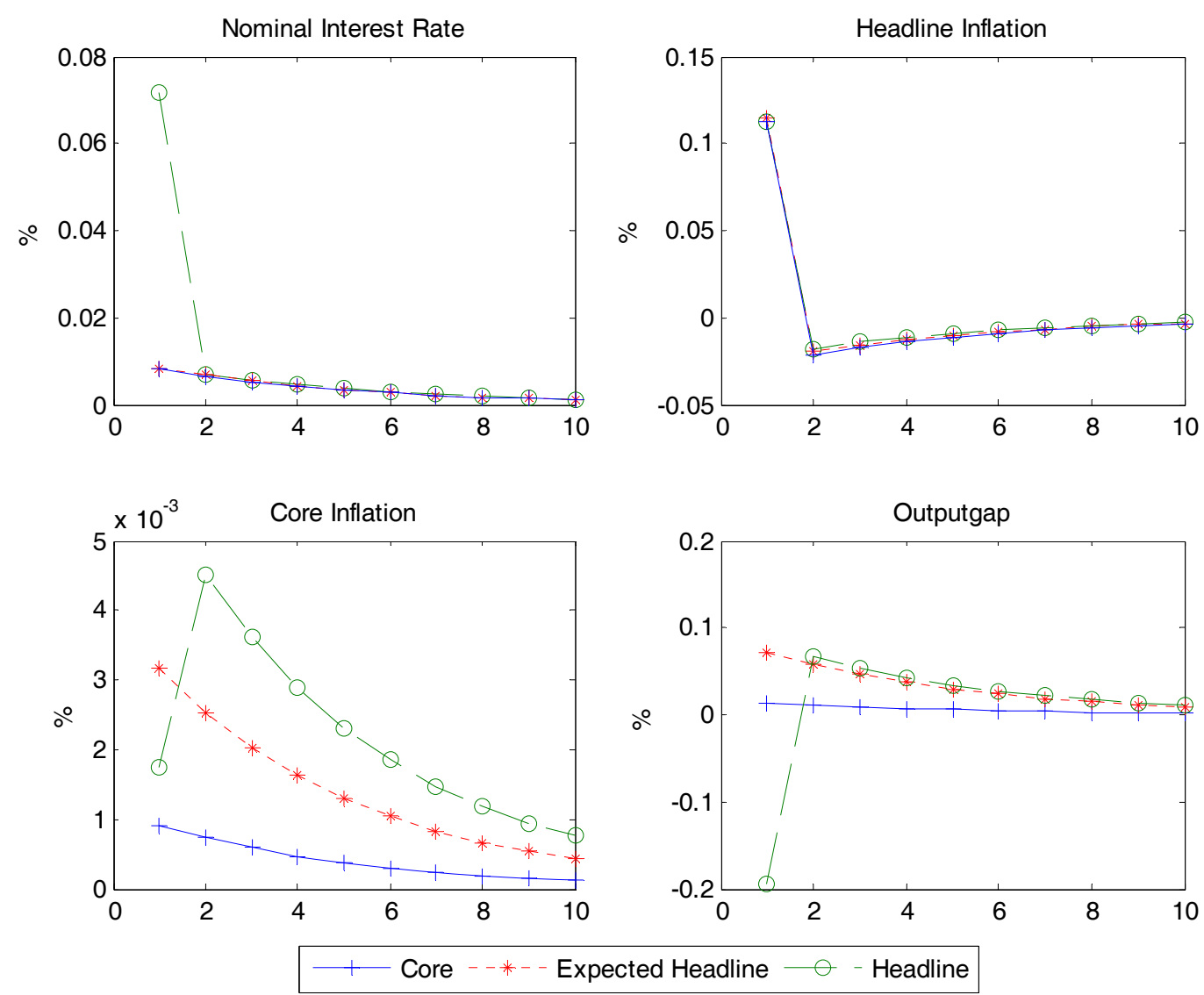

Figure 2: Responses of nominal variables and the output gap to a permanent increase in commodity prices
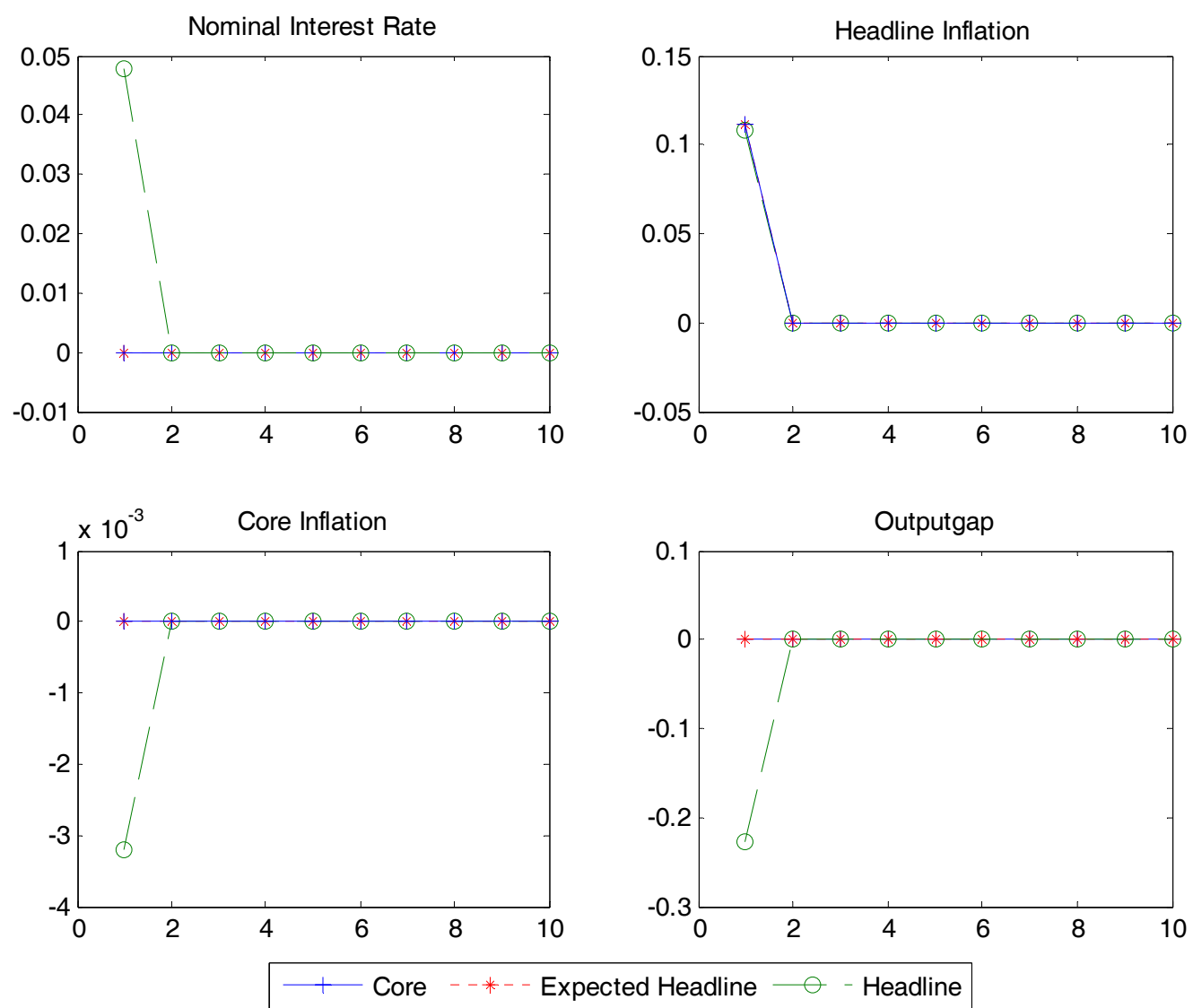
It can be shown that, according to the model, core inflation remains the superior monetary target in case of permanent shocks to commodity price inflation. The effects are easily understood when one considers a modified new Keynesian Phillips curve in terms of headline inflation.

(12) $\pi_{t}=\beta E_{t} \pi_{t+1}+\kappa \gamma\left(y_{t}-y_{s, t}^{n}\right)+\kappa \frac{1-\gamma}{c} x_{f, t}+\frac{1-\gamma}{\gamma} \Delta x_{f, t}-\beta E_{t} \frac{1-\gamma}{\gamma} \Delta x_{f, t+1}$

In the case of permanent shocks to $\Delta x_{t}^{f}$ equation (10) and equation (12) have a similar shape but a different intercept. ${ }^{9}$ Since the intercept of the Phillips curve in terms of headline inflation is larger when a permanent increase in oil price inflation occurs, output losses are bigger if central banks try to keep headline inflation stable. The output losses are the result of the permanent trade-off between inflation and output, which can be derived from the new Keynesian Phillips curve. Since core inflation must decline permanently if central banks focus on headline inflation, it seems to be better to stabilize core inflation in this case as well. However, Ascari and Merkl (2008) show that this trade-off stems from the fact that the model is linearized around zero inflation in both sectors. If the true, non-linear model is considered, the output effect crucially depends on the inflation level around which the model is linearized. If inflation in the sticky price sector exceeds a critical level, the effects of permanently depressing inflation by focusing on CPI inflation would be positive rather than negative.

Table 1 summarizes the implications of the standard NKM for the choice of inflation indicator. Only one case can be detected where headline inflation is the optimal target for monetary policy and that is, if the shock to commodity price inflation is permanent and core inflation was initially above its optimal level. Note that the expansionary effects of reducing core inflation in this case would also occur without a commodity price shock. It follows that focusing on headline inflation is never preferable provided that prior to the shock monetary policy was successful in stabilizing core inflation at its low, optimal value. To use Table 1 for monetary policy in practice one needs to know the optimal level of inflation in the sticky price sector of the economy. Ascari and Merkl (2008) show that the optimal level is very low, approximately 0.5 percent. However, in practice measuring inflation involves errors and, for several reasons, the measurement error has a positive bias. Therefore, as a reasonable assumption, the optimal level of inflation might well be in line with the ECB's inflationary objective of 'below but close to 2 percent'.

\footnotetext{
${ }^{9}$ Here, $\Delta x_{f, t}$ follows an $A R(1)$ process, $\Delta x_{f, t}=\rho_{\Delta} \Delta x_{f, t-1}+u_{\Delta, t}$. In the case of a permanent shock to commodity price inflation $\rho_{\Delta}$ is set to 1 .
} 
Table 1: Optimal policy objectives

( $\rho_{\Delta}:$ shock persistency)

\begin{tabular}{|c|c|c|}
\hline & \multicolumn{2}{|c|}{$\pi_{s}$ before shock to $\Delta x_{f, t}$} \\
\hline & > optimal level & $\leq$ optimal level \\
\hline$\rho_{\Delta}<1$ & $\pi_{s}$ & $\pi_{s}$ \\
\cline { 1 - 1 }$\rho_{\Delta}=1$ & $\pi$ & $\pi_{s}$ \\
\hline
\end{tabular}

In a nutshell, the analysis of an energy price shock in the standard new Keynesian model yields the following conclusions: A hitherto successful central bank should strive to stabilize core inflation. If there is no real wage rigidity, the effect on inflation will be temporary whether the initial shock is permanent or not. In the case of a temporary shock, i.e. one that is reversed in the near future, a Taylor rule based on actual (rather than forecast) headline inflation, will cause output to decline more and inflation to be more unstable than a Taylor rule based on core inflation, i.e. the consumer price index excluding energy. An inflation-targeting central bank would hardly react to the price shock at all.

\section{Two extensions}

Next we discuss the two most important extensions of the standard NKM, specifically modeling commodities as inputs in production ${ }^{10}$ and the assumption of real wage rigidity. None of the modifications dramatically change the implications for the optimal monetary target.

The results discussed above do not change qualitatively when commodities are also used in production. In case of the standard NKM, more expensive commodity imports lower the natural output level in both sectors in a similar manner as adverse technology shocks. When the commodity is not only a consumer good but a factor input as well, there are not only direct effects on the price level but also indirect effects as the higher production costs lead to successive indirect increases in the level of prices. These indirect effects are thought to peter out within one year (Fisher/Marshall 2006: 2). If the output objective is interpreted to be the level at fully flexible prices, the central bank can achieve a zero output gap and keep core inflation equal to zero by targeting core inflation.

A different situation arises if there is a high degree of real wage rigidity. In this case, the direct and indirect impact of the oil price shock on the price level is amplified by secondround effects. No matter what monetary policy strategy is followed, the temporary increase in inflation will be greater, and the monetary restriction and output decline more pronounced. Given real rigidities, the central bank faces a trade-off between output stabilization and inflation stabilization (Blanchard/Gali 2008: 4).

\footnotetext{
${ }^{10}$ In Germany, for instance, $70 \%$ of all energy imports are used as inputs in production.
} 
Given a temporary or permanent price level shock, the Taylor rule based on actual (rather than expected) headline inflation, would cause output to decline more but headline inflation to be more stable than would a Taylor rule based on core inflation. Second-round effects would be greater in this case. For an inflation-targeting central bank, the choice of inflation target does not greatly affect the outcome because expected inflation is targeted. As the central bank does not react to the initial jump in inflation, monetary policy is less restrictive than if the Taylor rule is applied. In the case of a temporary shock, targeting future core inflation yields more stable inflation (Duval/Vogel 2008: 6). The effects of real wage rigidity, i.e. the trade-off central banks are confronted with, are generally larger the lower nominal price rigidities. The worst-case scenario for practical monetary policy is therefore an economy with highly rigid real wages and highly flexible prices.

Given a permanent increase in commodity price inflation, central banks must reduce core inflation permanently to keep headline inflation stable. As mentioned above, the permanent positive trade-off between output and core inflation is an artifact of the linearized new Keynesian model. In the true non-linear model the trade-off is only positive if core inflation was initially below its optimal level. Ascari and Merkl (2008) show that real wage rigidities also aggravate the effects of permanent changes in core inflation. Targeting headline inflation is therefore only optimal if core inflation was above its optimal level before the permanent shock to commodity price inflation occurred.

All in all, our simulations show that substantial output losses would occur if central banks attempted to stabilize headline inflation when faced with commodity price shocks. A focus on headline inflation is only adequate, if there is a permanent change in commodity price inflation and the initial level of core inflation was above its optimal level.

\section{Core inflation and expectations}

Central banks aim for low and stable inflation because, firstly, high inflation increases the variability of inflation and thereby the uncertainty in economic decisions. Secondly, high inflation causes distortions as a result of the non-indexation of taxes and by raising transaction costs, for example. Thirdly it leads to arbitrary redistribution, as for instance, between borrowers and lenders or owners and renters.

The goal of monetary policy is to stabilize headline inflation over the medium term. Our new Keynesian simulations show that in the event of commodity price shocks monetary policy achieves better results when focusing on core inflation. In these models future headline and core inflation are known to all economic agents. In practice, focusing on core inflation is furthermore an attempt by central banks to discern whether underlying inflation is changing. ${ }^{11}$ So as not to react too strongly to transitory changes in inflation, core inflation can serve as a proxy for headline inflation in the short term (Mishkin 2007: 1). Accordingly Blanchard/Gali

\footnotetext{
${ }^{11}$ It is therefore not, as Krugman (2008a) points out, "a nefarious scheme to ignore the real hardships people face".
} 
(2008) without further comment use core inflation in their new Keynesian simulations of the monetary policy response to oil price shocks, which rely on the contemporaneous rather than the future rate of inflation.

A key question is how to calculate core inflation. First round effects include not only the direct impact on the price level but also the indirect effects as higher commodity costs are reflected in other goods and services. The consumption price index excluding energy and food can serve as a proxy, but the excluded categories include goods and services that are only minimally affected, whereas some of the included ones are greatly affected by the rise in commodity prices, such as public transportation. ${ }^{12}$

Central banks that emphasize core inflation and underlying inflation in communicating with the public may positively affect inflation expectations, thereby aiding the economic adjustments subsequent to an exogenous price shock. Expectations play a crucial role in the transmission of shocks (and of monetary policy) according to the new Keynesian model. Prices are changed at large intervals, so that price setters take expected future inflation into account when setting prices. Anchored expectations, i.e. high central bank credibility, should also make price-wage spirals less likely. Bean (2005) attributes to anchored expectations the fact that inflation expectations remained unchanged despite high increases in the price of oil: "...market participants believed that central banks would be able to pursue a more relaxed monetary policy in order to offset the adverse demand effects of the oil price increase without having to worry about setting in train a wage-price spiral of the sort seen in the 1970s" (Bean 2005: 12; see also Bean 2008: 6f.). ${ }^{13}$

\section{How should the ECB react to the price shocks of 2007/2008?}

A key question the ECB currently faces is whether real wages in the euro area are highly rigid or not. So far, there are only very limited signs of a wage price spiral. In some countries, such as Italy, wage increases are too high given the rate of productivity increase, but there has not been a pickup in the rate of wage increases there. In the euro area as a whole, hourly wage costs are increasing at a rate of $2.8 \%$ which is well within the bounds of productivity increase plus inflation target. There has been an increase in wage rises of late, but this is at least in part due to a return to normality in Germany, where nominal wages increases were well below real productivity increases for several years.

If the price shocks currently affecting the euro area were transitory, the policy advice would be obvious. The ECB should not react to the increase in inflation, because the effects

\footnotetext{
${ }^{12}$ Mishkin (2007: 8) cites studies that evaluated different measures of core inflation and conclude that none can said to be superior per se.

${ }^{13}$ Blanchard raises the question of whether the case for expectations may be overstated in the new Keynesian model: "One may reasonably ask, however, whether a price setter, choosing prices for the next month or the next quarter, will change his decision depending on what his expectation of inflation is, say, in five years. Put another way, while we very much want to believe it, I am not sure we actually understand whether and how anchoring of inflation expectations is so important. (Blanchard 2008: 21).
} 
of monetary tightening would be felt when headline inflation has declined below the inflation target due to falling oil prices. A policy reaction would in this case increase the variability of both inflation and output. But even if the shock is permanent, headline inflation will be affected only in the short run provided there are no second-round effects. ${ }^{14}$ Although it could be argued that monetary restriction is warranted because the increase in the price of oil lowers potential output, output itself is lowered by the oil price shock as well, as incomes are lower and negative wealth effects emanate from the less favorable terms of trade.

By explaining why some measure of core inflation is an important indicator in the face of commodity price shocks the ECB could try to further stabilize inflation expectations as headline inflation temporarily exceeds the target close to but below $2 \%$. The recent increase in medium and long run inflation expectations suggests that the ECB was not completely successful in communicating these issues to the public. In our view, the lack of communication rather than the commodity price shock is the reason for potential problems in stabilizing inflation expectations in the euro area.

As Buiter (2008) rightly points out, ${ }^{15}$ inflation is a sustained rise in the price level. Negative price shocks, that do not give rise to second-rounds effects, only increase the rate of inflation temporarily. ${ }^{16}$

\section{References}

Aoki, K. (2001): Optimal monetary policy responses to relative-price changes. Journal of Monetary Economics, Vol. 48, 55-80.

Ascari, G., and Merkl, C. (2008): Real wage rigidities and the cost of disinflations. .Journal of Money, Credit, and Banking, forthcoming.

Atkeson and Kehoe (1999): Models of Energy Use: Putty-Putty versus Putty-Clay. American Economic Review, Vol. 89, 1028-43.

Bean, Ch. (2005): Monetary Policy in an uncertain world. Speech at Oxonia Distinguished Speakers Seminar, The Oxford Institute of Economic Policy, Oxford, February.

Bean, Ch. (2006): Commentary: Impact of Globalization on Monetary Policy, speech delivered at the Federal Reserve Bank of Kansas City 30th Annual Economic Symposium, Jackson Hole, Wyoming, August.

\footnotetext{
${ }^{14}$ It should be noted that low real wage rigidity in the face of a supply shock does not necessarily result from flexible wages per se, but could be due to nominal rigidity of wages. In this case real wages decline automatically as inflation rises in response to higher oil price.

15 "For practical purposes, a representative price index that rises for more than two years would indicate inflation..." (Buiter 2008).

${ }^{16}$ Buiter then goes on to argue, however, that the increase in commodity prices is the result of an overly expansionary global monetary policy. It is hard to argue, however, that the ECB policy has been an important factor in pushing up the price of oil, and even harder to argue that the ECB should tighten the monetary reigns to effect a more restrictive global monetary environment. In a similar vein, the IMF recently argued that the Fed should focus on core inflation when faced with commodity price shocks (International Monetary Fund (2008: 114).
} 
Bean, Ch. (2007): Is There a New Consensus in Monetary Policy? In: Is there a new consensus in macroeconomics? Chapter 9, 13 April 2007. Proceedings of a conference on the state of macroeconomics organised by the Government Economic Service.

Bernanke (2004): The Logic of Monetary Policy. Remarks before the National Economists Club, Washington, D.C. , December 2, 2004.

Blanchard, O. J. (2008): The state of macro. Working Paper 08-17, August 2008. Massachusetts Institute of Technology, Department of Economics, Working Paper Series.

Blanchard, O. J. and Gali, J. (2008): The macroeconomic effects of oil price shocks. Why are the 2000s so different from the 1970s? Massachusetts Institute of Technology, Department of Economics, Working Paper 07-21, August 18, 2007, revised: March 25, 2008.

Buiter, W. (2008): Inflation here, there and everywhere. Maverecon Blog, Financial Times, May $14^{\text {th }}$, 2008.

Calvo, G. A. (1983): Staggered prices in a utility-maximizing framework. Journal of Monetary Economics, Vol. 12 , 383-398.

Clarida, R., Gali, J., Gertler, M. (1999): The Science of Monetary Policy: A New-Keynesian Perspective. Journal of Economic Literature, December, 1661-1707.

Duval, R. and Vogel, L. (2008): Oil price shocks and the conduct of Monetary Policy: Some Lessons from a New Keynesian perspective. OECD Economics Department Working Paper No. 603.

Fisher, E. O’N. and Marshall, K. G. (2006): The Anatomy of an Oil Price Shock. Federal Reserve Bank of Cleveland, Commentary, Nov. 2006.

International Monetary Fund (2008): World Economic Outlook. Fall 2008, Washington.

Krugman, P. (2008a): Embedded vs. non-embedded inflation. New York Times, May 31 ${ }^{\text {st }}, 2008$.

Krugman, P. (2008b): A return of that 70's show? New York Times, June $2^{\text {nd }}, 2008$.

Lenza, M. (2007): Monetary policy and core inflation. Deutsche Bundesbank Discussion Paper Series 1: Economic Studies No. 35/2007.

Mankiw, N. G. (2005a): Comments on "Separating the Business Cycle from Other Economic Fluctuations," by Robert E. Hall. Jackson Hole Conference, August 2005.

Mankiw, N. G. (2005b): Comments Presented at Federal Reserve Conference. Price Dynamics: Three Open Questions, Harvard University, September 2005.

Mishkin, F. S. (2007): Headline versus core inflation in the conduct of monetary policy. Remarks at the Business Cycles, International Transmission and Macroeconomic Policies Conference, HEC Montreal, Montreal, 20 October 2007. BIS Review 118/2007.

Svensson, L.E.O. (2008): What have economists learned about monetary policy over the past 50 years? Sveriges Riksbank, January 2008.

Woodford, M. (2003): Interest and Prices: Foundations of a Theory of Monetary Policy. Princeton: Princeton University Press. 
Publisher: Hans-Böckler-Stiftung, Hans-Böckler-Str. 39, 40476 Düsseldorf, Germany

Phone: +49-211-7778-331, IMK@boeckler.de, http://www.imk-boeckler.de

IMK Working Paper is an online publication series available at:

http://www.boeckler.de/cps/rde/xchg/hbs/hs.xls/31939.html

\section{ISSN: 1861-2199}

The views expressed in this paper do not necessarily reflect those of the IMK or the Hans-Böckler-Foundation.

All rights reserved. Reproduction for educational and non-commercial purposes is permitted provided that the source is acknowledged.
Hans Böckler Stiftung

Fakten für eine faire Arbeitswelt. 